\author{
MINA RAMÍREZ MONTES
}

INSTITUTO DE INVESTIGACIONES ESTÉTICAS, UNAM

\title{
José Mariano Oriñuela y su proyecto para el establecimiento de una Academia de Matemáticas en Querétaro
}

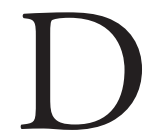

URANTE el Último CUARTo del siglo XViII, la Nueva España recibió un gran impulso de transformación procedente de la Península, pues las ideas ilustradas imperantes en esta última se difundieron desde su capital y llegaron a tener la misma intensidad, aunque tropezaron con mayores dificultades porque los trámites burocráticos en América eran más lentos.

Las reformas borbónicas pretendían centralizar el poder y controlar mejor las tareas administrativas, por lo que exigían modificaciones en la Real Hacienda, el comercio, la minería, el ejército, la educación y el espacio urbano en general. Las ciencias experimentales cobraron mayor importancia: la física, las matemáticas, la química, la medicina, las ciencias naturales y la geografía, entre otras. En Europa se crearon infinidad de academias. En España se fundaron algunas de matemáticas y en la Nueva España, dentro de la Real Academia de las Tres Nobles Artes de San Carlos, se instauró la cátedra de matemáticas. Dentro de este contexto surgió la idea de establecer en Querétaro una Academia de Matemáticas. En este artículo destacaré el entusiasmo del perito agrimensor y facultativo de minas José Mariano Orińuela por llevar a cabo ese cometido. Sólo como referencia mencionaré a Vicente Tosca, que en I686 fundó en

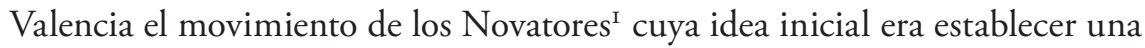
especie de academia matemática. Desde el siglo anterior, en España, Juan de Herrera, eminente arquitecto de Felipe II, ya había creado una.

I. Científicos y filósofos empiristas y racionalistas. 
Pero ¿qué pasaba en una ciudad alejada de la metrópoli peninsular y cercana a la capital de la Nueva España? La perspectiva era la siguiente:

Querétaro a finales del siglo xvin era una de las principales ciudades del virreinato, se ha dicho que la tercera, por su población, agricultura, fábricas y comercio [...] Sus moradores pasaban de 50,000, sus fábricas menores de algodón y lana eran 400 y las mayores, en que se tejen paños y bayetas, $20 .^{2}$

Los diezmos, la renta del tabaco y las alcabalas correspondían a una economía floreciente. José Mariano Oriñuela había nacido en Santiago de Querétaro hacia $1753 .{ }^{3}$ Fueron sus padres José Antonio Oriñuela y Antonia Herrera. El gentilicio Oriñuela u Orihuela se menciona en los documentos queretanos desde el siglo XVII, por lo cual se supone que, si bien procedía de españoles, ya varias generaciones de ese apellido habían vivido en esta ciudad, donde José Mariano pasó su infancia, juventud y los últimos años de su vida. Por razones de trabajo, residió algún tiempo en Guanajuato, donde conoció a María de Jesús Acevedo, ${ }^{4}$ originaria del real de Marfil, con quien se desposó el io de noviembre de 1787 en Querétaro.5 Con ella procreó a María Ignacia Antonia Rosalía, a quien bautizaron el 4 de septiembre del año siguiente. ${ }^{6}$ Quizá tu-

2. Carta enviada al rey por el ayuntamiento (Santiago de Querétaro, 2 I de julio de I 80o) para solicitarle la creación de un obispado en esta ciudad. Cfr. Mina Ramírez Montes, Ars Nove Hispania. Antología documental del Archivo General de Indias, México, Universidad Nacional Autónoma de México-Instituto de Investigaciones Estéticas, 2005, vol. I, doc. núm. I 39.

3. Oriñuela dijo tener 46 años en 1799 en el testimonio presentado en un pleito entre Juan Fernández Munilla contra Tomás López de Ecala. Archivo General de la Nación (en adelante AGN), Tierras, vol. 36I8, cuad. 2, f. I8v. No he podido localizar su fe de bautismo, a pesar de haberme empeñado en ello. El deseo de encontrarla responde a la intención de poner límites a su vida y a su obra.

4. Ella se había casado antes con Juan José Trujillo, con quien engendró a María Josefa Valentina Trujillo Acevedo, a la que se bautizó en la parroquia de San José y Santiago de Marfil el 20 de febrero de 178r. Cfr. Archivo Parroquial del lugar.

5. "José Mariano Orińuela, natural de esta ciudad, vecino de la estancia de Villela, hijo de José Antonio Orińuela y de Antonia Herrera, con María de Jesús Acevedo, originaria del real de Marfil, viuda de Juan José Trujillo. Padrinos Ignacio Oriñuela y doña María Altamirano. Testigos José Noriega y Anastasio Reséndiz", Archivo Histórico de la Parroquia de Santiago de Querétaro (en adelante AHPSQ), Libro de matrimonios de españoles, M-8, f. I 85 .

6. Fe de bautismo de María Ignacia Antonia Rosalía, AHPSQ, Libro de bautismos de españoles, B-I 4, f. 2 I. 
vieron más hijos, pero ello se desconoce. Poco se sabe de la vida familiar de Orińuela y respecto a su carácter hablaremos al final.

Su carrera primaria fue el comercio y la pluma por cuya rara habilidad se concilió la estimación con personas de primera distinción, y con mucha especialidad con el memorable corregidor que fue de esta ciudad el licenciado don Martín José de la Rocha. La fuerza de su ingenio perspicaz le hizo girar por la aritmética [...] es casi el único agrimensor de esta su patria, venciendo su talento hasta las escabrosidades del álgebra; naturalmente es fecundo y elegante para la prosa en la cual no halla dificultad alguna sobre cualquier asunto, y no menos lo sería en el verso, pero no ha querido fundar por este camino el encomio a su grande ingenio. ${ }^{7}$

El 28 de febrero de I785, José Mariano Oriñuela, vecino y minero de Querétaro, solicitó al Tribunal de Minería se le practicara el examen para obtener el título de perito medidor de minas:

Digo: que hallándome instruido teórica y prácticamente en las ciencias y artes, que, según las Reales Ordenanzas, deben saber los peritos facultativos de minas; y teniendo asimismo instrumentos propios y correctos para las operaciones de medidas, que debidamente presento, en conformidad del artículo $2^{\circ}[\ldots]$; se ha de servir la justificación de vuestra señoría de mandar que se reconozcan y se me examine en las referidas facultades y juzgándome apto se me libre el título correspondiente. ${ }^{8}$

El título I7 del artículo I ${ }^{\circ}$ de las Reales Ordenanzas estipulaba lo siguiente:

Para que las Minas puedan trabajarse con acierto y seguridad y conseguir completamente el logro de sus riquezas, es menester que las operaciones se dirijan por hombres bien instruidos en los principios y reglas que ministran las Ciencias naturales y prácticas, y las Artes conducentes, y á quienes la experiencia propia haya enseñado su justa y conveniente aplicación. Por tanto, y para que los dueños de minas no equivoquen la elección de los sujetos que empleen juzgando inteligentes á los que sólo tienen una instrucción superficial y de palabras, ó á los que no los acredita mas que el preciso

7. Manuel Septién e Ignacio Herrera, Cartografía de Querétaro. Colección de 35 planos de la ciudad y del estado, Manuel Septién (introd.), Querétaro, Gobierno del Estado de Querétaro, I978, adiciones al plano 25. Apud José Mariano Acosta Enríquez, "Jardín de Apolo", ms.

8. Archivo Histórico del Palacio de Minería (en adelante AHPM), I793/II/6I/d. 20, f. 3. Los documentos citados se presentan en versión paleográfica modernizada. 
transcurso del tiempo que han vivido en los reales de minas sin reflexión ni ciencia alguna, y sin tener otro título que la recomendación de sus compañeros, siendo por otra parte equívoca y difícil la calificación de sus errores voluntarios y maliciosos, lo cual conduce á los mineros á una ciega y peligrosa confianza en lo más importante de su negocio, y les ha ocasionado graves perjuicios: á fin de que éstos puedan evitarse, y los peritos se hagan dignos de la fe pública y judicial en las cosas de su arte, ordeno y mando que en cada real de minas haya uno o muchos sujetos inteligentes, instruidos y prácticos en la geometría, y en la arquitectura subterránea e hidráulica, y también en la maquinaria, y en las artes de carpintería, herrería y albañilería en la parte que se usa de ellas en el ejercicio de las minas, los cuales se llamen peritos facultativos de minas.

Los dichos peritos facultativos de minas tendrán los instrumentos necesarios y suficientes para los casos que puedan ofrecerse en la práctica de medidas de minas así subterráneas como superficiales, los cuales deberán estar siempre exactos, correctos y arreglados, de manera que no falten a la debida puntualidad y regularidad en las operaciones; para lo cual serán vistos y reconocidos al tiempo que se examinaren y se les despachen sus títulos y después en las visitas extraordinarias. ${ }^{9}$

Oriñuela, en cumplimiento de las Ordenanzas de I783, declaró llevar sus herramientas precisas. $\mathrm{El} 4$ de marzo del mismo año fue examinado por Joaquín Velásquez de León, quien señaló:

en la teórica y práctica de las operaciones de medir minas, trazar y dirigir sus obras en que pretende titularse; lo hallo suficientemente instruido e idóneo. Asimismo he reconocido los instrumentos que presenta y son de la propia construcción y regular exactitud que los que usan otros peritos aprobados. Por lo que no hallo embarazo para que vuestra señoría en cumplimiento de la Ordenanza que cita se sirva de mandar que, previo el juramento acostumbrado, se le despache el título de perito medidor de minas que pretende. ${ }^{\text {Io }}$

El examen era muy rutinario y, aunque ponía a prueba la experiencia, podríamos decir que era sólo un trámite burocrático, pues todos los expedientes conocidos dicen lo mismo. Quizá lo más difícil era llegar hasta el Tribunal de

9. Reales Ordenanzas para la dirección, régimen y gobierno del importante cuerpo de la minería de Nueva España y de su Real Tribunal General de orden de su majestad, facsímil, México, Sociedad de Ex Alumnos de la Facultad de Ingeniería, 1976, pp. I 8 I-I 84 [primera ed. impresa I786].

Iо. АHPM, $1785 / \mathrm{III} / 20 /$ d. 24 , f. $2 \mathrm{v}$. 
Minería, trasladarse a la ciudad de México desde el lugar de origen y permanecer algunos días en ella. Oriñuela prestó juramento seis días después:

Habiendo comparecido ante los seńores presidente, administrador y diputados generales del Real Tribunal General de la Minería de esta Nueva España en la sala de su despacho don José Mariano Orińuela: yo el infrascrito secretario en conformidad del auto del día de ayer le recibí juramento que hizo por Dios nuestro Señor y la señal de la santa cruz, so cuyo cargo prometió usar bien y legalmente, según su leal saber y entender, sin fraude, disimulo y con imparcialidad del cargo de perito medidor de minas $[\ldots]$ en los casos pertenecientes a esta profesión, y al mismo tiempo juró defender el misterio de la Purísima Concepción de María Santísima señora nuestra desde el instante primero de su ser. Y, dando gracias a dichos señores por la merced que les ha merecido, concluyó esta diligencia que firmo de que doy fe y de conocerle. José Mariano Oriñuela ${ }^{\text {II }}$

Siete años después el perito medidor de minas requería un testimonio de su título; trabajaba por entonces en el mineral de Guanajuato y tuvo que volver a solicitarlo así:

Habiendo encontrado personas de poco discernimiento que no califican por bastante dicho título; así por carecer de las expresas palabras de "facultativos de minas" con que distingue la Ordenanza artículo I ${ }^{\circ}$ título I7, a los que se ocupan en sus medidas y dirección de obras, como por faltarle la cláusula exhortatoria recomendativa del empleo a las diputaciones y justicias territoriales, me hallo en necesidad de pedir [...] a vuestra seńoría que para quitar toda duda y poder ejercer libremente todas las funciones relativas a mi profesión, se me refrende el indicado título, con la especificación y ampliación oportuna. ${ }^{\mathrm{I}}$

Al no poder presentarse en la ciudad de México personalmente, dio poder al presbítero Mariano Cardoso para que tramitara el documento, que se le expidió el I I de julio de I792. ${ }^{\text {I3 }}$

Gran parte de su vida la dedicó Oriñuela a hacer valuaciones de casas, huertas, fincas rústicas, solares, tierras de sembradío y haciendas — como

I I. Ibidem, f. 3 .

I2. Ibidem, f. I.

I3. Ibidem, f. 6. 
las de Santa Bárbara, la Capilla y Vanegas-, entre otras, que generalmente acompañaba de algún plano. También opinó sobre el acueducto y el enzolve de las fuentes. ${ }^{I 4}$ Alguna vez tuvo que alternar con Francisco Eduardo Tresguerras para proponer reparaciones y medidas con que se garantizaría el desagüe del río de la Laxa hasta la presita de Enríquez y con que se contribuiría a evitar las inundaciones sufridas por la ciudad de Celaya y el camino de Salvatierra. Ambos valuadores debían presentar por separado sus apreciaciones sobre el asunto, y la de Orińuela comenzaba con estas palabras: "Para que no se dude de los fundamentos que tengo en esta resolución, los paso a demostrar matemáticamente". En cambio, Tresguerras empezaba por descalificar a Orińuela y vanagloriarse de sus conocimientos acerca de Celaya. Entre varias frases elogiosas referentes a sí mismo, al mencionar a Oriñuela como autor de las calzadas y puentes, señaló:

no sé cómo pueda dictaminar desapasionado, pues dichas obras son sus hijas [...] y pruebo que les profesa un cariño más que regular. Conferenciando con el dicho dije que sus obras las creía dańosas, pues encajonada la corriente de las aguas entre el bordo de la saca, pared del convento de San Juan de Dios y la calzada levantada por su dirección, retrocedían, reposaban lamas y obraban poderosas hacia el obstáculo menos resistente. ${ }^{\mathrm{IS}}$

Como las opiniones sobre el problema eran muy encontradas, hubo que nombrar a un tercer perito que dirimiera la cuestión. En determinados avalúos, Oriñuela hacía gala de sus conocimientos matemáticos y de geometría sin llegar a la presunción, pero no puedo demostrarlo ahora, por lo que me centraré en lo que considero lo más interesante de su trabajo teórico, con fines educativos, y lo que me motivó a estudiar su labor y su preocupación por la enseñanza de las matemáticas.

En Querétaro, la educación elemental se impartía a los niños en la escuela de los padres de la Compañía de Jesús. Las niñas, en cambio, se instruían en los conventos de monjas y en los beaterios. Para quienes creen que en los monasterios femeninos sólo se enseñaban manualidades, mencionaré un "tratado de matemáticas” que Ignacio Rivera escribió en 1797 para sor María de

I4. AGN, Historia, vol. 439, exp. I 8, ff. 8-I I.

I 5. AGN, Tierras, vol. 2072, exp. I, cuaderno 5, ff. I-33v. 
la Concepción, del convento de Santa Clara de México. ${ }^{16}$ Los "estudiantes" - supongo que tanto jóvenes como adultos- aprendían en el salón general del Colegio de San Francisco Xavier. Infiero que aprendían la gramática y las artes, cuyo estudio correspondía en el siglo XviII al grado de bachiller, título que permitía el ingreso a la Real y Pontificia Universidad de México. Si bien ello fue así sólo hasta I767, 2I años después se aprobó la reapertura del Colegio de San Francisco Xavier, sin la presencia jesuita. Los planes y programas se desconocen hasta ahora, pero se recomendaba atender la escuela de primeras letras y los mismos estudios mayores de antaño. La prueba de que era necesario cultivar en otro centro las ciencias exactas, en especial las matemáticas, la constituye la propuesta de Orińuela, que el ayuntamiento apoyó.

El 6 de enero de I792, el perito agrimensor invocó sus méritos y ponderó su dedicación al solicitar al virrey permiso para fundar una academia de matemáticas:

Don José Mariano Orińuela, residente en la ciudad de Querétaro y perito facultativo, medidor de minas, examinado y titulado por el Real Tribunal General del importante cuerpo de Minería de esta Nueva Espańa, con el mayor respeto a vuestra excelencia, dice: que desde el año de 1785 que fue examinado en dicha facultad se ha empleado en varias operaciones relativas a ella, en medidas y avalúos de tierra y en algunas negociaciones de agricultura, sin haber podido adquirir un fondo moderado para sostener a su familia con algún descanso, y habiendo contraído últimamente algunos accidentes que le impiden tolerar la fatiga de bajar y subir a las minas, ${ }^{17}$ ha deliberado radicarse en esta ciudad su patria, y para servicio de ella establecer una academia o escuela pública, de gracia para los pobres y de paga para los que tengan comodidad, donde se dedicará a enseñar a la nińez y juventud los principios matemáticos que contiene el plan de gobierno, que con la mayor sumisión pasa a manos de vuestra excelencia, y considerando que para verificar este proyecto con algún distintivo que lo haga recomendable es indispensable impetrar el superior permiso de vuestra excelencia, se ve precisado a exponer a su alta comprensión las razones que le mueven a esta solicitud.

16. Libro de cuentas con las cuatro reglas de aritmética explicadas para el uso de la muy reverenda madre sor María Francisca de la Concepción, religiosa del velo y coro en el convento de nuestra madre Santa Clara. Escrito con la mayor claridad por el maestro examinador don Ignacio Rivera. Año de I797, ms. en la Biblioteca del Congreso de la Unión. Cfr. Josefina Muriel, Conventos de monjas en la Nueva España, México, Santiago, I946, p. I 54.

I7. Debido a una lesión en una pierna. 
Dicha ciudad es de las más numerosas y sobresalientes de este reino y, sin embargo, no se conoce en ella agrimensor titulado u otro profesor alguno de matemáticas que pueda dar instrucción al público para que jamás falten sujetos hábiles en aritmética, geometría, trigonometría, arquitectura, estática, hidráulica, nivelación y otros ramos necesarios para la exactitud en el manejo del comercio, minería y agricultura; para el desempeño de las funciones de contadores, agrimensores y apreciadores de tierras, aguas y fábricas y directores de obras, en cuyas operaciones se interesa el bien común, la buena administración de justicia y la subsistencia de algunas comunidades, capellanías, viudas o menores, que no pocas veces pierden sus fondos por cargarse a censo sobre fantásticos valores calculados erróneamente por sujetos imperitos en los principios conducentes.

Igualmente pueden criarse muchos individuos aptos para el real servicio en los cuerpos de infantería, ingenieros, artillería y marina, por ser esta ciudad más que alguna del reino la que surte a las banderas de mayor número de reclutas y todos los sujetos que hallen con instrucción matemática podrán ser destinados en dichos cuerpos y le profesarán más amor al servicio por la distinción que lograrán en su carrera. Estando inmediato Querétaro a otras ciudades, muchos pueblos y algunos reales de minas podrán ocurrir allí con más brevedad y menos gasto por los prácticos que necesiten para las operaciones de geometría y arquitectura. ${ }^{\text {I } 8}$

A continuación transcribo el plan de enseñanza:

REFLEXIONES QUE MUEVEN AL ESTABLECIMIENTO DE UNA ESCUELA O ACADEMIA DE PRINCIPIOS MATEMÁTICOS PARA LA PÚBLICA INSTRUCCIÓN EN LA CIUDAD DE Querétaro, hechas por José Mariano Oriñuela, originario de Dicha CIUdAD, Y FACULTATIVO MEDIDOR DE MINAS, EXAMINADO Y TITULADO POR EL REAL TRIBUNAL General del importante cuerpo de Minería de esta Nueva España.

Todas las cosas constituyó Dios en número, peso y medida, como dijo el sabio, ${ }^{19}{ }^{*}$ y por eso ninguna ciencia como la matemática, que tiene por objeto toda cantidad mensurable, le da al hombre una cabal idea de cuánto comprende la dilatada esfera de la naturaleza.

I8. AGN, Historia, vol. 499, exp. 5, f. 82.

I9. "Omnia in mensura et numero et pondere disposuisti, véase Sap., cap. I I, v. 2 I" [nota del original]. 


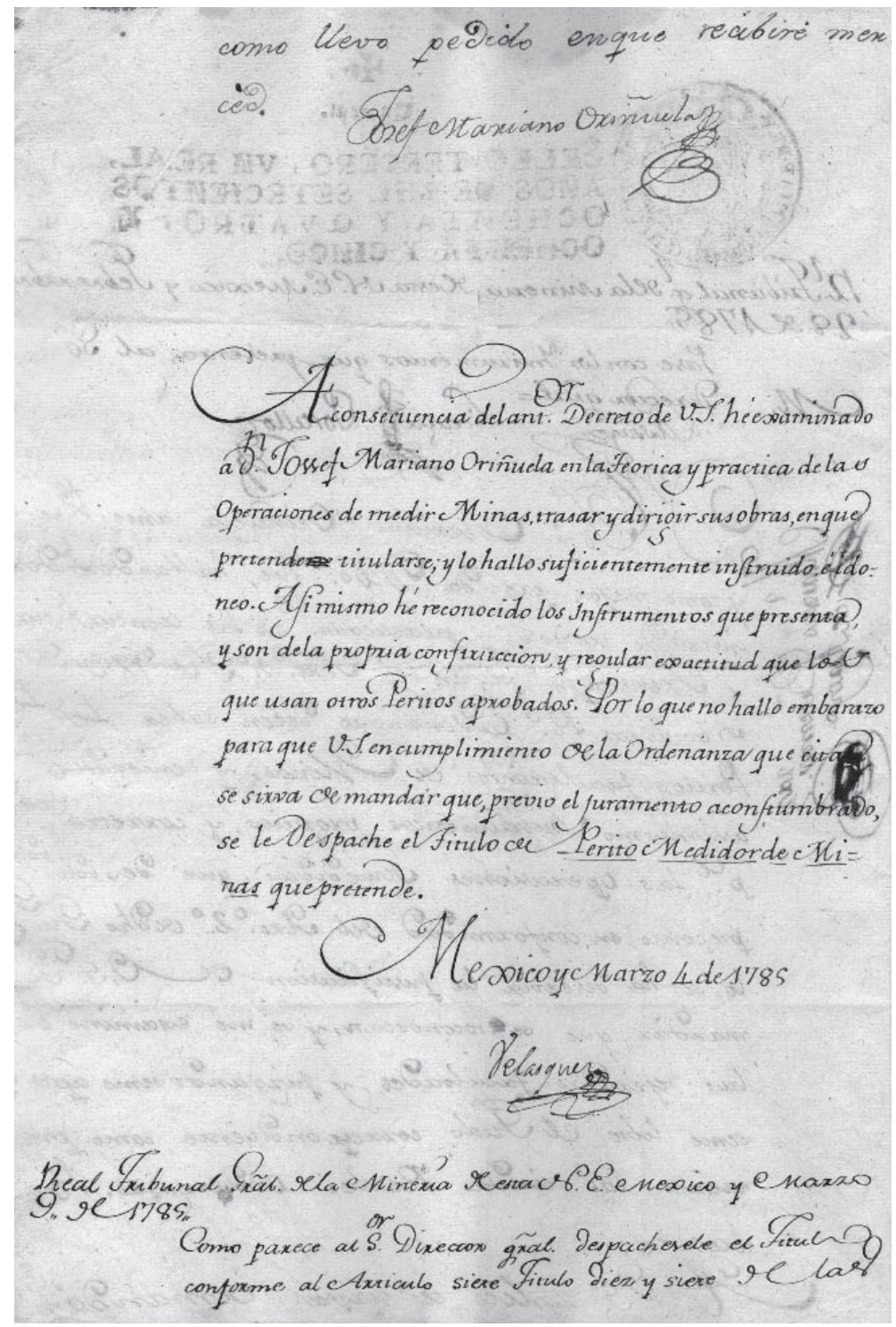

I. Dictamen del señor director del Real Tribunal General de la Minería de esta Nueva España donde da cuenta de haber examinado a José Mariano Oriñuela, México, 4 de marzo de 1785. Archivo Histórico del Palacio de Minería, I785/ III $/ 20 /$ d. 24 , f. 2 v. 
De aquí es que los profesores de matemática no sólo sean útiles, sino necesarios en las repúblicas, pues contribuyen a su ornamento, comodidad y defensa; a la buena administración de la justicia distributiva; a la perfección y lustre de los artes liberales y mecánicos, al incremento del comercio, minería y agricultura, a la fuerza de las armas y buen orden de las acciones de guerra; a los aciertos de la náutica y con estos auxilios a la extensión de las monarquías y de la religión.

La Real Academia de San Fernando y el seminario de San Telmo en España son perpetuos y brillantes testimonios del real celo de nuestros católicos monarcas, y serán siempre las madres más fecundas en cuyo seno se nutren excelentes matemáticos para los cuerpos del ejército y marina, para la carrera del comercio y para la maestría de obras públicas.

A imitación de tan augustos ejemplares se ha movido nuestra Nueva España a erigir la Real Academia de San Carlos para la enseñanza de las tres nobles artes de pintura, escultura y arquitectura, a establecer cátedra de matemáticas en el Colegio de San Juan de Letrán, y a fundar el Seminario de Metalurgia y Mineralogía del Real Tribunal de Minería, a fin de que se cultiven y propaguen aquellas ciencias y artes en que tanto se interesa. ${ }^{20}$

Inspirado de tan nobles máximas y deseoso de hacer algún servicio a la patria, siendo instrumento de que algunos nińos o jóvenes de esta ciudad se ejerciten en las matemáticas, he pensado abrir una escuela o academia pública donde por el orden que se expresa y bajo el gobierno que se prescribe se les darán las lecciones siguientes:

ELEMENTOS QUE SE HAN DE ENSEÑAR DE ARITMÉTICA

- Definiciones y diferencias de los números: sumar, restar, multiplicar y dividir enteros.

- Sumar, restar, multiplicar y dividir quebrados.

- Sumar, restar, multiplicar y dividir cantidades fraccionarias.

- Transformación de quebrados en otra especie y valúo de ellos.

- Sumar, restar, multiplicar y dividir números complejos y dividir decimales.

- Utilidad de los decimales para facilitar los cálculos.

- De los números cuadrados y extracción de raíces.

- Casos en que son necesarias estas reglas.

- De los números cubos y extracción de sus raíces.

20. En esta reflexión Oriñuela olvidó mencionar la cátedra de matemáticas instituida en la Real y Pontificia Universidad de México, que, desde I646, ocupó fray Diego Rodríguez y, más tarde, Carlos de Sigüenza y Góngora. 
UTILIDADES DE ESTAS REGLAS

- De la regla de tres simple y directa.

- De la regla de tres simple e inversa.

- De la regla de tres compuesta.

- Regla de compañías simples y compuestas.

- Regla del cuatro o infracta agregación.

- Reglas del tanto por ciento o aneajes. ${ }^{2 \mathrm{I}}$

- De aligaciones o mezclas.

- De falsas posiciones.

- De las razones y proporciones aritméticas.

- De la progresión aritmética.

- De la razón y proporción geométrica.

- De la progresión geométrica.

DE ÁLGEBRA

- Caracteres y signos del álgebra.

- Sumar, restar, multiplicar y dividir algebraicamente.

- Ecuaciones de primer grado.

- Ecuaciones de segundo grado.

- Cuestiones que se resuelven por álgebra con menos trabajo que por números.

DE GEOMETRÍA

- De las definiciones y proposiciones de esta ciencia.

- De las líneas.

- De los ángulos y su medida.

- De las superficies y figuras.

- De los triángulos y su medida.

- De los cuadriláteros y su medida.

- De los polígonos y su medida.

- De los círculos y su medida.

- De la esfera y su medida.

2I. Acción de medir por anas ("antigua medida de longitud que equivalía aproximadamente a un metro", véase el Diccionario de la lengua española, Real Academia Española, Madrid, 200I). 
- De los cubos y paralelepípedos.

- De los cilindros y prismas.

- De las pirámides y otros sólidos.

DE LAS MEDIDAS DE COMPARACIÓN

- De los sitios de ganado mayor y menor y sus partes menores.

- Del modo de medir solares y su valúo.

- Del modo de medir fábricas y su aprecio con reglas de estereometría para el cálculo de los materiales que contienen.

- De las medidas de campos dilatados y su valúo con respecto a su ubicación, calidad y frutos que llevan.

- Medidas de distancias inaccesibles.

- Método para levantar planos de medidas practicadas.

- Método para formar el mapa de un país. ${ }^{22}$

- De los instrumentos matemáticos más usuales y necesarios.

- Modo de medir las minas y su laborío.

- De la arquitectura y sus órdenes.

- De la medida y división de las aguas, modo de valuarlas y nivelarlas según reglas de hidráulica.

- Aplicación de la aritmética y geometría a casos prácticos del comercio, agricultura y otras artes liberales y mecánicas, reglas útiles a toda suerte de personas.

Por el orden [en] que quedan sentados estos principios se irán enseńando en todos los días de trabajo, siendo tres horas de ocupación por la mañana y dos a la tarde. La primera hora, de mańana y tarde será de lecciones que dará el maestro a los discípulos y las últimas de estudio y examen del aprovechamiento de cada uno, preguntándoles el maestro el método con que comenzaron y acabaron el cálculo u operación que se les encargó a fin de evitar los plagiados o falsedades que suelen cometer, con pérdida del tiempo y de la aplicación propia.

22. En I 802 él hizo un plano de la ciudad, donde "está indicado todo el sistema hidráulico de Querétaro: la acequia madre, las fuentes públicas y el acueducto, el que aparece incluso con sombras para dar idea de su altura". La diferencia respecto a los planos anteriores estriba en "que éste está realizado con instrumentos", por lo que es el primer plano que resulta con estas características. Véase Carlos Arvizu García, "Padrones, planos y ordenanzas. Espacio urbano en Santiago de Querétaro, I778-I 802", en Juan Ricardo Jiménez (coord.), Querétaro a finales del siglo XVIII. El padrón de I79I, Querétaro, Instituto de Estudios Constitucionales, 2008, pp. I IO-I I 3. 


\section{REFLEXIONES 7} que mueven al establecumiento de una Escuela o Atcademia ge principios matematicos, para la publica instruccion

ciz la ciudad de Guemetamo. FIECHAS

Por Jose Marizano Orinuela originaxio de decha Ciudad, y Jacuteatibo clredidor de cltinas, examirado y tivulado porel 2 . Tribun. Grál del Importante cuexpo de cltinewa de cota eslera España.

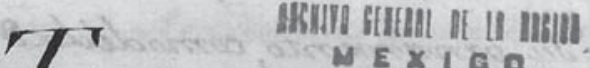

Lodar las cosas conutzizú Dusi en nu mexo peso y medida, como difo el wabio* If pux eso ninguna ciencid como (a) matematica que tiéne pox objeto toda * ominia ir menvura et numera et pondere disposuist: Sap. Cap.12. +21

2. Portada de las Reflexiones que mueven al establecimiento de una escuela $o$ academia de principios matemáticos para la pública instrucción en la ciudad de Querétaro. Archivo General de la Nación, Historia, vol. 499, exp. 5, f. 59. 
Este ejercicio será indispensable todos los días a excepción del sábado que se distribuirá en la forma siguiente:

A las siete de la mañana se congregarán en la escuela todos los discípulos, y formados en columna a estilo de las demás pasarán al templo más inmediato con la mayor compostura a oír misa en obsequio de la Inmaculada Concepción de Nuestra Señora, y concluida se retirarán a la escuela en la misma forma.

Desde la hora que llegaren hasta las io del día se ocuparán los discípulos unos con otros en conferenciar sobre las cuentas que han aprendido en toda la semana, examinando los más instruidos a los que no lo están, el modo con que las sacaron, para que este ejercicio les sirva de repasar todo lo que han practicado y sobre ello se harán sus preguntas y réplicas y propondrán sus dudas, las cuales aclarará el maestro y satisfará a todas las que se le promovieren para mejor ilustrar el asunto que trataren.

De las io a las i i hará el maestro un examen preguntando a cada individuo el todo o parte de la tabla de aritmética que deberán saber todos completamente, y según el grado en que se hallen les hará formar de memoria adiciones, sustracciones, multiplicaciones y divisiones integrales y fraccionarias de dos o de más guarismos, con cuyo ejercicio se disciplina imponderablemente el ingenio, se fija la atención y provee la memoria de muchas noticias de agregados, diferencias y resultados que ocasionan unas cantidades unidas o comparadas con otras; y lograrán más aprovechamiento en un mes con este método que tal vez en un año con el común que se practica en las escuelas ordinarias, donde apenas se les da una lección sola y se le recibe sin más examen que la prueba de la demostración que las más veces es trabajada por otro.

Igual ejercicio se hará a los geómetras preguntándoseles la declaración de algún teorema o el modo de resolver algún problema aritmética o geométricamente, para que tanto en la especulativa como en la práctica tengan la destreza que corresponde, sin confundirse ni embarazarse.

A la tarde se leerá media hora en un libro dogmático como Luz de verdades católicas, [el del] padre Belarmino, etcétera, u otro para precaver que ningún discípulo grande o pequeńo con la distracción del estudio olvide el mayor de los negocios, y se preparen para emplear bien el día de fiesta consagrado a Dios, la suprema majestad, y acabada la lección se rezará la Corona de María Santísima y se retirarán todos a su casa.

Acabando de ejercitarse en toda la aritmética y álgebra, llevará cada discípulo su cuaderno en blanco, y a lo menos una regla y un compás para ir copiando las líneas y figuras geométricas que se les pondrán a la vista como modelo en una estampa grande, además de la explicación y reglas que se les darán para describirlas, cuyas lecciones irán trasladando en el mismo cuaderno, para encomendarlas a la memoria mediante el estudio. 
Llegándose a tratar de la geometría práctica, no sólo se les instruirá del método de resolver las cuestiones trabajando en el papel, sino que por mayor se les describirán en el terreno las mismas figuras para que sepan proceder en ambos casos con pericia.

Después que sepan en el papel y terreno medir y resolver cualquier figura, cuyos términos sean accesibles, se les darán reglas para observar y medir distancias inaccesibles, verticales y horizontales, con el arbitrio de triángulos auxiliares cuando lo fragoso del terreno u otros obstáculos no permiten otra cosa, cuyas operaciones ocurren muchas veces en las medidas de montañas, barrancos o tránsitos de ríos.

A los arquitectos no sólo se les harán entender los cinco órdenes de arquitectura civil, sus proporciones, ornamento y distribución, sino cuanto pertenece a la hidráulica para construcción de presas, molinos, etcétera, necesarios para la agricultura y la composición de mezclas de la mejor consistencia.

$\mathrm{Y}$, en una palabra, teórica y prácticamente se les dará idea de cuanto conduce a la medición y avalúo de todo género de tierras y fábricas urbanas y silvestres, y de cuanto queda expresado en estos principios con la extensión conveniente para que en todas las negociaciones y ocurrencias de la vida pueda el practicante manejarse con tino y exactitud huyendo de engańarse y de ser engańado.

Vuestra excelencia.

Querétaro, diciembre 29 de I79I

José Mariano Orińuela [rúbrica] ${ }^{23}$

Se advierte en este programa de estudios la influencia del Compendio matemático de Tosca y de los Principios de matemáticas de Bails de I776. He de mencionar que en I79I se requirieron Ioo ejemplares del segundo libro porque hacían mucha falta para instruir a los alumnos del Seminario de Minería. ${ }^{24}$ Oriñuela reveló también su conocimiento de los tratados de arquitectura y matemáticas en I80o, cuando justificó el diseño de los planos que había elaborado para la alameda, y puso de manifiesto su gusto por el estilo contemporáneo, es decir el neoclásico. ${ }^{25}$

Mientras el intento de fundar la Academia de Matemáticas en Querétaro conseguía su objetivo, otra tentativa semejante se realizaba en Jalapa, donde José María Alfaro pretendía crear una escuela de varias artes donde se enseñara aritmética, álgebra, geometría, arquitectura, geografía y dibujo. ${ }^{26}$

23. AGN, Historia, vol. 499, exp. 5, ff. 59-66.

24. AGN, Correspondencia de virreyes (Revillagigedo), vol. I62, f. I 38.

25. AGN, Obras públicas, vol. 37 , exp. I 3 (véase el "Apéndice").

26. AGn, Historia, vol. 499, exp. 7, ff. I 3 I-I 57. 
Recibida la propuesta de Orińuela en la Secretaría del Virreinato, se turnó al fiscal, quien pidió que la solicitud se acompañara con el título de medidor de minas del autor y con un informe del ayuntamiento de Querétaro. Hubo una demora por el título faltante, pero una vez recuperado éste continuaron los trámites. En septiembre, el ayuntamiento respondió que, supuesta la aptitud de Oriñuela, no veía perjuicio alguno en la fundación, que antes bien podía resultar provechosa.

Sin embargo, hubo que atender más requerimientos, pues en noviembre del mismo año el expediente se sometió a la aprobación de la Real Academia de San Carlos, ya que el asunto era de su competencia. El director de matemáticas, Diego de Guadalajara Tello, declaró que las leyes de dicha academia ${ }^{27}$ prohibían fundar instituciones de enseñanza sin licencia real y sin fondos para su subsistencia. Sin embargo, no dudaba que los preceptos que el suplicante deseaba difundir fueran muy útiles, y por tanto planteaba la posibilidad de conceder la apertura provisional. Luego de presentarse Orinuela al examen correspondiente, para saber si tenía la ciencia necesaria, añadió el director de arquitectura, Antonio Velásquez, que el pretendido instituto de Querétaro debería quedar sujeto a la Real Academia, y que para expedir títulos primero debería tenerlo el pretendiente y que, por tanto, los estudios enumerados en la solicitud podrían hacerse sin las formalidades expresadas si el solicitante se contentara con nombrar escuela a su establecimiento y a sí mismo maestro de ella, y no aspirara a una verdadera academia ni menos al honor de titularse director, pues esto requería un conjunto de circunstancias que no concurrían. ${ }^{28}$

A Orińuela se le notificó en diciembre y en enero siguiente contestó que no podría presentarse de inmediato a las pruebas por hallarse ocupado en la valuación de una testamentaría en Cadereyta. En julio acudió al examen y Diego de Guadalajara Tello dijo al respecto:

27. Artículo XXIX, núm. 7: "Mando que no se pueda fundar en Nueva Espańa estudio alguno de las artes, sin que primero se me dé cuenta por medio de esta Academia, del establecimiento que se intente, de sus medios de subsistir, y método para su gobierno. En caso de estimarlo conveniente, no sólo concederé el permiso necesario para la fundación, sino también las gracias y privilegios que le sean adaptables de la misma Academia, a la cual ha de quedar subordinada, como todas las que se establecieren en Nueva España”. Cfr. Estatutos de la Academia Nacional de San Carlos de esta capital y leyes posteriores pertenecientes al mismo establecimiento, México, Tipografía de R. Rafael, I 852, p. 5 I [primera ed. I785].

28. AGN, Historia, vol. 499, exp. 5 , f. 95 v. 
En presencia del señor conciliario don Antonio Basoco, y del señor secretario de esta Real Academia don Antonio Piñeiro, [Diego de Guadalajara Tello examinó] a don José Orińuela (la noche del 5 de que rige), en geometría y trigonometría, en tasaciones de tierras y fábricas rurales, en hidráulica, nivelación y repartimientos de aguas, y en todo satisfizo completamente resolviendo los problemas que se le propusieron, y a mayor abundamiento le hice un examen privado en asuntos algebraicos y lo hallo en todo bien impuesto, y por tanto lo juzgo capaz de desempeñar el oficio de agrimensor que solicita, salvo el mejor juicio y la determinación del señor excelentísimo vice protector, a cuya justificación se servirá vuestra excelencia informar de la actitud del suplicante.

Sala de Matemáticas de esta Real Academia y julio I 5 de 1793 años. ${ }^{29}$

El virrey, luego de escuchar la opinión del fiscal, escribió a la Academia de San Carlos:

Constando por el informe que hace vuestra señoría con fecha de 30 de julio último, que don José Mariano Oriñuela se halla capaz de desempeñar la escuela de principios de Matemáticas que ha pretendido establecer en Querétaro y el oficio de agrimensor, le he concedido mi permiso para la apertura de aquella con las calidades y en los términos propuestos por los directores de Matemáticas y Arquitectura en el informe que hicieron en 7 de diciembre del año próximo anterior, que acompañó vuestra señoría a su oficio de igual fecha, y también para que sirva el citado oficio expidiéndole el título correspondiente, y lo aviso a vuestra señoría para su inteligencia y gobierno.

Dios guarde a vuestra señoría muchos años.

México, I4 de agosto de I793.

El conde de Revillagigedo ${ }^{30}$

No se sabe en qué edificio de la ciudad abrió sus puertas el establecimiento, pero muy probablemente lo hizo en la Academia de Pintura, también escuela de primeras letras, o en la propia casa de Oriñuela. En Querétaro no se conservan las actas de cabildo del virreinato y los cronistas guardaron silencio al respecto, pero lo que sí se sabe es que Oriñuela volvió a Querétaro para radicar ahí como era su deseo, al menos desde I79I, ya que forma parte del padrón levantado en

29. AGN, Historia, vol. 499, exp. 5, f. I I I.

30. Ibidem, f. I I 8. 
ese año, donde se anota que no era apto para el ejército por motivos de cojera. ${ }^{3 \mathrm{I}}$ Continuó también haciendo valuaciones de casas y de propiedades rurales. ${ }^{32}$ Es oportuno mencionar que hubo otros valuadores en su tiempo, pero de él se conserva un mayor número de apreciaciones, tanto en el Archivo Histórico de Querétaro como en el General de la Nación. En i8 Io se le menciona como "maestro", y ya no más, como siempre, perito, facultativo o agrimensor. Otra prueba de que tuvo discípulos la constituye el certificado que en I8I7 expidió a José Manuel Yáñez, donde orgullosamente indicó:

Ha estudiado y practicado bajo mi dirección en el tiempo de más de 4 años, la aritmética inferior, álgebra, geometría, trigonometría, estática, hidráulica, nivelación y cálculos logarítmicos, en cuyos principios se ha instruido suficientemente para ejercer con acierto las funciones de agrimensor. ${ }^{33}$

Yáñez presentó su examen en la Real Academia de San Carlos y "lo encontraron regularmente instruido". Otro indicio de las enseñanzas de José Mariano puede ser esta referencia: en I835, un joven llamado José María Oriñuela, probablemente su nieto, solicitó al virrey que se le admitiera en San Carlos para "concluir el curso de matemáticas, del que ya tenía principios".34

Una de las finalidades del estudio de las matemáticas era la aplicación de éstas en la arquitectura. Cuando José Mariano tuvo uso de razón, la mayoría de los templos virreinales queretanos estaban terminados y a él sólo le tocó ver la construcción del oratorio de San Felipe Neri, obra muy distinta de las demás pues su portada cabalga entre el estilo barroco y el neoclásico. Hablo de los templos y de su arquitectura porque Oriñuela incursionó también en el arte del diseño.

31. Jiménez, op. cit.

32. Glorinela González Franco et al., Artistas y artesanos a través de fuentes documentales. Ciudades, pueblos y villas, México, Instituto Nacional de Antropología e Historia, I995, vol. II, pp. I73-I74.

33. Archivo de la Real Academia de San Carlos (en adelante ARASC), gaveta I 2, ficha I 485 .

34. Eduardo Báez Macías, Guía del Archivo de la Antigua Academia de San Carlos, I80I-I 843, México, Universidad Nacional Autónoma de México-Instituto de Investigaciones Estéticas, 1972. Apud ARASC, gaveta I 5, ficha 2275. También es oportuno mencionar aquí que José María Montilla había solicitado al cabildo de Querétaro un pase para avecindarse en la ciudad y enseñar ahí matemáticas y elementos de arquitectura. Tal autorización se concedió el 22 de septiembre de I8 I 5. Cfr. ARASC, gaveta io, fichas I I 85-I I 89. Dos meses después, "El día 20 [de noviembre] abrió clase de matemáticas [...] previas las necesarias licencias". Apud Francisco Xavier Argómaniz, Diario de Querétaro, I807-I826, Querétaro, Gobierno del Estado de Querétaro, I979, p. I 52. 
José Mariano conoció seguramente al arquitecto Francisco Martínez Gudiño, perteneciente a una generación anterior y el más famoso de su tiempo en Querétaro, es decir en torno a la mitad del siglo xviII. Gudiño poseyó una gran biblioteca y entre los libros científicos de ella mencionaré algunos que también pudo haber conocido, tenido o leído Orińuela: los libros de arquitectura de Andrea Palladio, Francisco Borromino y fray Laurencio de San Nicolás; el que escribió sobre cantería el maestro Juan de Torija; Carpintería [de lo blanco], de Diego López de Arenas; Física experimental de Nolet; los nueve tomos [del Compendio mathematico] del padre Tosca; las dos primeras partes [del Museo pictórico y escala óptica] de Palomino, el Tratado de metales y el Tratado de meteoros, de Aristóteles. ${ }^{35}$ A la muerte de Gudiño, ocurrida en I775, sus libros debieron dispersarse, ya que los hijos que procreó en su segundo matrimonio eran pequeños y ninguno se dedicó a las labores del padre. Consta que Oriñuela conoció los de Vitruvio, Viñola, fray Lorenzo de San Nicolás, Tosca y, particularmente, el de matemáticas de Bails, del que hay notoria influencia en el programa de la academia o escuela que José Mariano fundó. ${ }^{6}$

Sin embargo, Orińuela no se inclinó por la arquitectura, aunque siempre estuvo muy vinculado con los terrenos y las construcciones al medirlos y valuarlos, y fue consciente de la importancia de las matemáticas en el quehacer del arquitecto, idea que seguramente había recogido de fray Lorenzo, quien consideraba la aritmética y la geometría pilares básicos de la formación profesional arquitectónica. ${ }^{37}$ Como diseñador, José Mariano delineó obras que más bien parecerían de ornato y que en apariencia son lo único que hizo: portadas, fuente, balaustrada circundante y torre de la alcantarilla de la alameda de Querétaro, ${ }^{38}$ terreno fértil al que llamó "un bello teatro de la naturaleza”. Los trabajos de este jardín se comenzaron en un gran espacio en los límites de la ciudad, hacia el sur, donado por Pedro de Acevedo, como parte de su hacienda de Casablanca. Se recibieron donativos y se organizaron corridas

35. Títulos o autores que provienen del inventario de los bienes de Francisco Martínez Gudiño. No se acostumbraba entonces consignar el título o el nombre del autor completos, AHQ, Justicia (antes Civil), I775.

36. Véase el Apéndice.

37. Antonio López Gayarre, "Fuentes bibliográficas de arte y uso de arquitectura de fray Lorenzo de San Nicolás", en Espacio, tiempo y forma, México, Universidad Nacional de Educación a Distancia-Facultad de Geografía e Historia (Serie VII, Historia del Arte), I990, t. 3, p. I 37.

38. AGN, Obras públicas, vol. 37, ff. I09-I I 5 , imágenes núms. 978/I368-978/1374. Reproducidas por varios autores y, en 2008, por Arvizu, op. cit., pp. I27-I 3 I. 
de toros para costear la realización. El proyecto para cercar la alameda era de estilo neoclásico y constaba de varios pórticos que, a manera de arcos triunfales de diferentes órdenes de arquitectura, se unían mediante una balaustrada perimetral con algunas fuentes en el interior. La obra pudo haberse comenzado en I797, justo cuando los planos se habían trazado, pero a éstos Antonio González Velásquez, director de arquitectura de la Academia de San Carlos, les encontró muchos defectos. Conocemos la defensa que de ellos hizo su autor en una carta enviada al virrey el 29 de diciembre de 1800 , donde se manifiesta su talento para escribir y para explicar la razón de las formas utilizadas en las puertas, así como su conocimiento de las obras y los autores clásicos en la arquitectura y las matemáticas. ${ }^{39}$ Por estos u otros motivos, poco se ha de haber realizado, ya que en I803 José María Zelaa, en sus Glorias de Querétaro, señalaba: "Está hasta ahora sólo comenzada una hermosa Alameda, que en llegándose a concluir será un delicioso paseo"..$^{\circ}$ Ello nos hace creer que en el lienzo de la ciudad pintado por Oriñuela un año antes la imprimió de manera ideal, muy bien trazada con árboles y en completo orden, pero las portadas no se aprecian. ${ }^{4 \mathrm{I}}$ Se hicieron algunos trabajos con posterioridad, pero todo quedó destruido durante el sitio de la ciudad de 1867 . El proyecto de Oriñuela pudo haberse realizado todo o en parte; sin embargo, cuando se concluyó, fue en un estilo diferente en la época porfiriana. Hoy tiene nuevas portadas, realizadas en el siglo pasado, que no corresponden a los planos de Oriñuela, pues se adoptaron en ellas elementos barrocos y neoclásicos sin el espíritu que animó a esos estilos. También se conservan los planos realizados por el agrimensor para las reformas que se pretendían en la alhóndiga de la ciudad de Querétaro. ${ }^{42}$

José Mariano Orińuela fue un

hombre de mucho juicio, serio de genio, de estatura regular, color trigueño y de corazón benigno. Lo vario de su fortuna lo ha hecho dedicarse al ejercicio que emprendió y enseñar en él discípulos hasta graduar uno y otro, pero su viveza le crió apto para música, arquitectura, agricultura y otras ocupaciones útiles a la humanidad. 43

39. Véase el Apéndice.

40. José María Zelaa, Glorias de Querétaro, México, Oficina de don Mariano José de Zúñiga y Ontiveros, I803, p. 5 .

4I. Vid. supra, n. 2 I.

42. AGN, Obras públicas, Contenedor I 5, vol. 37, exp. I 2, ff. I 8 5-I 87 y 246.

43. Septién y Herrera, op. cit., plano 25; apud Acosta Enríquez, op. cit. (n. 7). 
Falleció, siendo viudo, en Querétaro, el 2 de febrero de I8I9, y su cadáver fue sepultado en el templo de la Congregación. 44 Un franciscano se expresó así de él: "Agrimensor de profesión y de habilidad, de un porte honradísimo y carácter muy jovial y amable. Escribía en prosa con mucho acierto y hacía versos no despreciables, juntando a esto otras habilidades de un hombre fino y bien educado que lo hicieron estimado de todos". 45

44. AHPSQ, Libro de entierros de españoles, E-I I, I8 I6-i 822, f. 35v. Francisco Xavier Argómaniz se refirió así al recién fallecido: "Agrimensor titulado e igualmente muy buen vecino", en op. cit., p. 2 I 2.

45. Anónimo, Acuerdos curiosos, Querétaro, Gobierno del Estado de Querétaro, I988, vol. IV, p. $38 \mathrm{I}$. 


\author{
APÉNDICE \\ Defensa que José Mariano Oriñuela hizo de su proyecto \\ para la ALAMEda de la CiUdad de Querétaro. \\ Santiago de Querétaro, 29 De Diciembre De I80046
}

Muy ilustre señor

Las ocupaciones y enfermedades que he tenido en el presente mes y el pasado me han impedido cumplir con lo que vuestra señoría mandó en decreto de 30 de octubre, a fin de que expusiese lo conveniente sobre los defectos que ha anotado don Antonio Velásquez, director de arquitectura, en los planos que formé para la alameda de esta ciudad.

Quisiera ser tan sucinto en la defensa como lo fue el caballero Velásquez en la acusación, pero la generalidad en que ésta se apoya da motivo a especificar por menor los fundamentos de aquélla.

Confieso que cuando hice los diseños no sólo no tenía en la delineación de arquitectura la práctica de dos meses que supone, sino que fueron los primeros que ejecuté en mi vida. Si por esta razón carecen de la limpieza y hermosura que les hubiera dado la mano de un hábil práctico, no es justo se desprecie por eso, como no les falten los tamaños y proporciones que se requieren para la firmeza y comodidad. Estas dos propiedades sí que son esenciales de toda obra, $\mathrm{y}$ sin las cuales no pueden subsistir ni debe estimarse aunque goce un sumo grado de belleza, y por el contrario sin ella puede ser permanente y útil siendo sólida y apta para su destino que es el fin principal de la edificación.

Compruébase esta verdad con dos recientes ejemplares de obras cuyos planos han salido de la Real Academia, el primero de una famosa cúpula construida en la iglesia de San Francisco de la villa de San Miguel, que se cayó de su propio peso, no obstante de que su delicadeza, sencillez y gallardía le daban el aspecto más hermoso, y el segundo el arco del coro del santuario de Nuestra Señora de los Ángeles de México, el cual sin embargo de tener la deforme fealdad de dos columnas que lo sustentan puede durar así muchos siglos.

No hay duda que las cinco portadas de la alameda están arregladas a los preceptos de Vińola, cuya observancia no está prohibida, pero por lo mismo ni son solamente semejantes los órdenes que las distinguen ni yo los bauticé con 
sus nombres como se asegura. Este autor y otros muchos antiguos y modernos han confirmado con los de toscano, dórico, jónico, etcétera, toda composición arquitectónica cuyas columnas tienen de alto 7, 8, 9 y Io veces su diámetro, además de las molduras y adornos propios de su carácter, y así no hay motivo para que el director diga que yo inventé cosas extrañas.

Si reprobara la aplicación de distintos órdenes a un solo edificio tendría algún fundamento, porque según Bails a las páginas 629 y 630, tomo 9, parte primera de arquitectura, debe tener cada uno distinta aplicación; bien que contra esto se puede argüir que una alameda admite varia decoración en sus ingresos por ser un patio común con trozos de hidráulica, un lugar de inocentes recreaciones, un sitio de campo con magnificencia, un edificio público para todos los estados y un bello teatro de la naturaleza. Pero, como refuta solamente la falta de uniformidad, es preciso decir que el director no supo distinguir lo que es uniformidad de partes y lo que es uniformidad de cuerpos. Los miembros de un compuesto o fachada que se mira desde un punto demandan uniformidad, más cuando por su mucha longitud o elevación dan varios puntos de vista y que cuando son distintos los pisos debe ser diverso el ornato de puertas y ventanas, así lo enseña el mismo Bails número I485, página 778 , y se puede añadir a esto que aunque la alameda es un edificio aislado, cada una de sus puertas forma un cuerpo de arquitectura separado por el muro, o cerca, con más de 200 varas de distancia y que la monotonía siempre es fastidiosa a los ojos sensatos pues no encuentran deleite en ver una misma figura repetida.

Es cierto que pueden hacerse otros diseños de sencillez sin pobreza para el menos costo y de mayor gracia que los míos para el gusto; pero no por esto los debió el director calificar de ridículos. Lo serían sin duda si no tuvieran ejemplar en la ordenanza, sino de puro capricho y si sus adornos fueran impropios como símbolos sagrados, trofeos de guerra, cabezas de víctimas, etc. en lugar de ramos, rosetas, festones y jarras, cuyo atavío les di a pedimento de un individuo de este ilustre ayuntamiento que deseaba no fuese tan desnuda la construcción.

Aunque tengo bien comprendido lo sustancial de la arquitectura en lo teórico por Vitruvio, Viñola, fray Lorenzo, Tosca y particularmente por Bails, cuyos principios matemáticos he estudiado, en cuya virtud obtengo los títulos de facultativo de minas y agrimensor general, jamás me he usurpado el de arquitecto ni me he inferido en trazar ni dirigir obras, a menos de que se me encargue por no haber a la mano ningún profesor examinado. Si habiéndolo me eligiesen a mí los magistrados procederían contra lo que previenen los es- 
tatutos de la Real Academia números I, 2 y 3, artículo 29, pero por falta de él exige la justicia, apoyada en las leyes de la necesidad, se ocupen los inteligentes conocidos para que se hagan planos y remitan a la misma Academia para su rectificación, conforme a la ordenanza $7^{\text {a }}$ de Intendencias, la que no prohíbe por eso que los hagan sujetos no examinados; fuera de que en esta práctica se interesa el bien público por el ahorro de tiempo y gastos, pues con más equidad y presteza trabajan los artífices en su patria, por el amor que le tienen, que los extraños estando distantes o incomodándose en un largo viaje.

$\mathrm{Al}$ excelentísimo señor virrey, como vicepatrono, y a la junta superior de la Real Academia toca solamente declarar los sujetos que pueden o no dirigir obras públicas y hace mal el director de quererse arrogar esta autoridad concluyendo en su reprobación con que de ninguna manera sea yo el que dirija las de la alameda, por no estar calificado. Sólo recomiendo a la alta comprensión de los verdaderos jueces, si hallándose en mí, por beneficio divino, instrucción en las ciencias matemáticas, podrá acompañarme discernimiento para entender el arte de la arquitectura, cuyas reglas son tan claras y limitadas.

Querétaro, 29 de diciembre de I80o.

José Mariano Orihuela [rúbrica] 